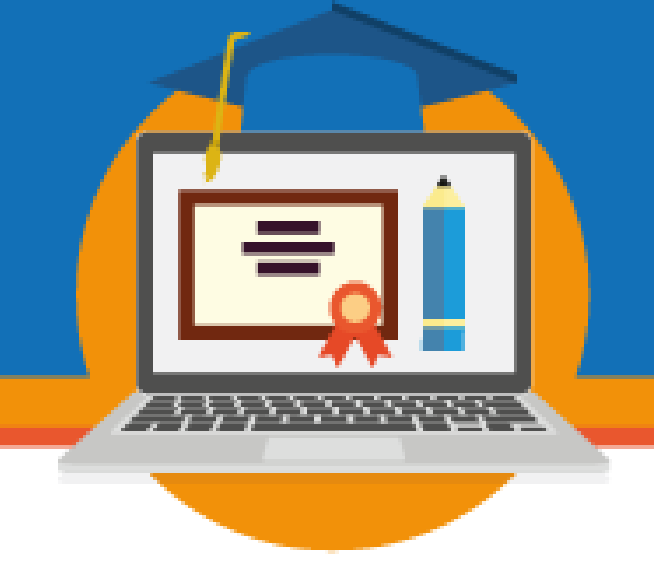

\title{
PRÁTICA DOCENTE E TECNOLOGIAS EDUCACIONAIS: UM ESTUDO DE CASO NOS ANOS INICIAIS DO ENSINO FUNDAMENTAL
}

\author{
Valdênia Rodrigues Fernandes Eleotério \\ Universidade Federal de Mato Grosso do Sul-Brasil \\ valdeniaeleoterioufms@gmail.com \\ Adriana da Silva Ramos de Oliveira \\ Universidade Católica Dom Bosco-Brasil \\ adrianaramosuniderp@gmail.com \\ Sulamita Barreto Nascimento \\ Universidade Federal de Mato Grosso do Sul-Brasil \\ soroka-80@hotmail.com
}

\section{RESUMO}

O artigo tem como tema a prática docente e as tecnologias na educação. Apresenta reflexões de um Trabalho de Conclusão de Curso, o objetivo foi compreender as dificuldades dos professores em utilizar tecnologias como recurso pedagógico. É um estudo de caso, de natureza qualitativa, com metodologia de uma pesquisa bibliográfica/de campo. Os resultados revelam os desafios que os professores têm enfrentado nas escolas. Conclui-se que o tema necessita de debates, para que os professores possam desenvolver práticas ativas para despertar nos alunos, desde o início da formação escolar a consciência científica, o pensamento crítico e o princípio ético na tomada de decisões para que possam construir o conhecimento com significado.

Palavras-chave: Prática docente; Metodologias ativas; Tecnologia.

\section{INTRODUÇÃO}

$\mathrm{Na}$ Sociedade da Informação e Comunicação o avanço tecnológico frenético tem provocado mudanças comportamentais nos sujeitos e práticas sociais. No contexto educacional não é diferente, as instituições tentam reestruturar não só os espaços físicos, mas também o currículo escolar. A socialização, que agora acontece por diversos canais, muda completamente à construção cultural da identidade individual e coletiva. Essas e outras transformações (política, econômica, cultural), deixam o professor com o desafio de oferecer uma aula 


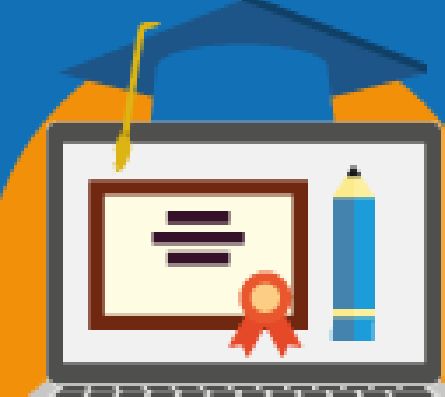

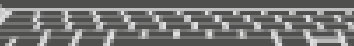
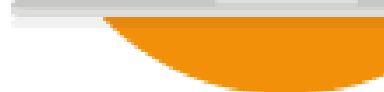

dinâmica, atrativa, conforme observado na pesquisa de campo, realizada em duas escolas (municipal e estadual), no município de Aquidauana (MS).

Os problemas de pesquisa que guiaram a construção do trabalho tiveram como foco as interrogações: como ensinar os nativos digitais de maneira que o aprendizado tenha significado para eles? Existe algum programa de formação continuada para os professores sobre a utilização de tecnologias educacionais? Caso haja formação, existem acompanhamentos dos Núcleos de Tecnologias Educacionais (NTE) ${ }^{1}$, em relação aos resultados obtidos? O que os Professores Gerenciadores das Tecnologias Educacionais e Recursos Midiáticos (PROGETECs) fazem para auxiliar os professores na adaptação dos conteúdos aos recursos tecnológicos? Para responder a esses questionamentos o texto foi estrutura em três sessões.

\section{NATIVOS DIGITAIS: COMO ENSINAR A GERAÇÃO NET}

De acordo Jenkins (2006), a sociedade atual é banhada diariamente por um dilúvio de informações e é obrigação dessa mesma sociedade ensinar seus filhos a nadar, a flutuar e principalmente a navegar nesse mar, uma vez que à queda dessa água não têm data certa para cessar. Nesse universo, onde tudo converge com o uso dos recursos midiáticos, às interações são instantâneas, onde alunos de todas as faixas etárias, no seu cotidiano acessam computadores, aparelhos celulares.

Com tudo isso, percebe-se na literatura que quando o assunto é educação e tecnologia, abrem-se muitas discussões, de uma complexidade desafiadora, pois na educação os resultados de aceitação não são imediatos e logo, se pode saber, se o que foi posto é funcional ou não. Mudanças na educação exigem um planejamento minucioso, uma vez que seus resultados são mais lentos chegam a dez, quinze ou até mesmo vinte anos para que se tenha de fato mudança. A esse respeito Freitas (2008) escreve que:

[...] o computador e a internet ainda são colocados de fora da sala de aula. São vistos apenas como um recurso tecnológico à sua disposição, mas não reconhecem neles, as suas reais potencialidades para

${ }^{1}$ É uma estrutura descentralizada, de nível operacional, do ProInfo, vinculada à SED e especializada em TIC aplicada à educação, de acordo com a diretriz de critérios de criação e implantação emitida pelo MEC/FNDE. (MATO GROSSO DO SUL, 2015). 


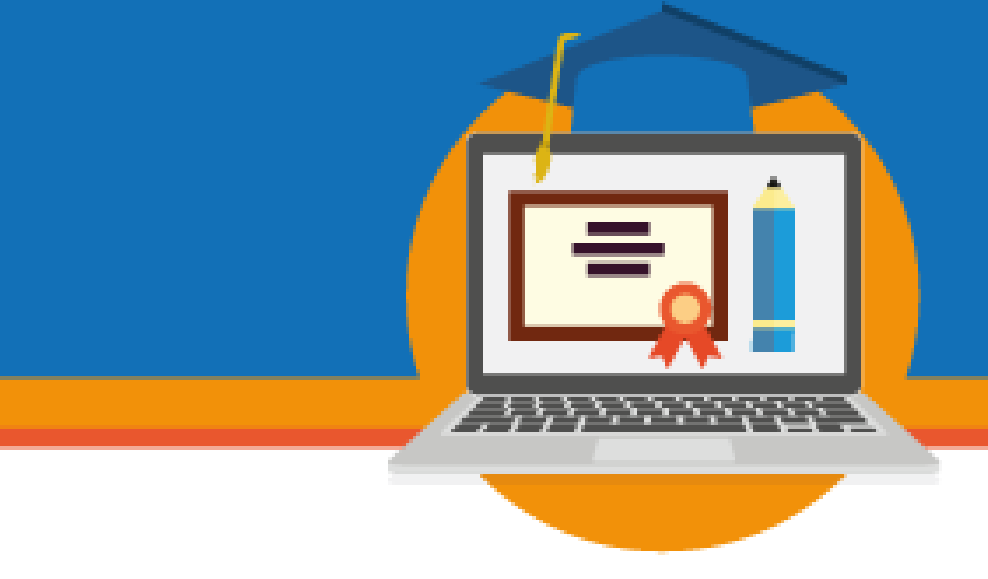

serem incluídos como instrumentos de aprendizagem que revolucionem a prática pedagógica [...]. (FREITAS, 2008, p. 70).

A autora nos diz que não somos alheios, mas resistentes às mudanças, os professores sentem-se confrontados diante desse letramento digital de seus alunos e percebendo-se deles distanciados, alguns se sentem até ameaçados, por não dominarem esses recursos. Vêm a introdução das mídias nas escolas como desnecessária. Sabemos que tem professores com perfis diferentes, mas todos têm o mesmo objetivo, a maneira de tornar suas aulas dinâmicas, numa escola caracterizada por salas de aulas cheias de alunos com grau de concentração cada vez mais baixo, com insatisfação com a escola e os conteúdos didáticos.

Na realidade, o sistema educacional não se preparou para o curso que a sociedade toma na atualidade. Capacitar os professores para utilizar as tecnologias educacionais é primordial. O que esses educadores precisam compreender é que as velhas instituições têm em seus bancos um novo perfil de aluno, o nativo digital que passa maior parte do seu tempo conectado. Os alunos mudaram, pois diferente das gerações passadas, nasceram imersos nesse ambiente tecnológico, não só no contexto familiar, mas em todas as esferas que compõem essa sociedade. A partir das socializações nas redes, desenvolvem conhecimentos ainda que não científicos, mas, que lhes dão condições necessárias para interagir, ensinar, aprender enquanto compartilham e produzem informações.

Abreu (2009), diante do exposto diz que alguns professores, já perceberam a maneira diferenciada que esses nativos digitais se portam nas escolas, com relação a esse fluxo de trocas contínuas. Para ela, a preocupação desses educadores é com a forma desprendida que eles lidam com tudo, construindo as próprias estratégias, sem a condução devida para o despertar do senso crítico que é fator necessário para o desenvolvimento do conhecimento científico.

Os estudantes de hoje - desde a pré-escola até a faculdade - são a primeira geração a crescer com essa nova tecnologia digital. Eles passaram a vida inteira cercados de computadores, vídeo games, DVD players, câmeras de vídeo, celulares, sites de leilões online, iPods e todos os outros brinquedos e ferramentas digital, usando todos eles. (PRENSKY, 2010, p. 58).

Para Prensky (2010), como os alunos, que falam uma nova linguagem digital, recebem as informações com rapidez, são capazes de realizar várias tarefas ao mesmo tempo, preferem 


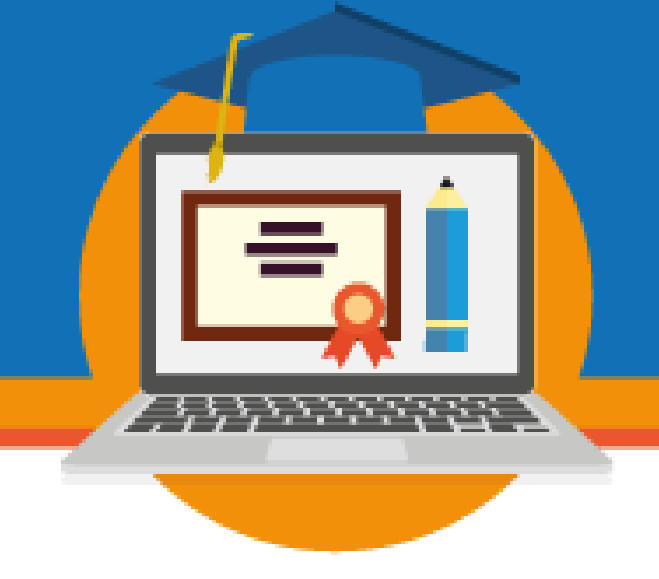

as imagens e não os textos como fonte de comunicação primária e passam a maior parte do tempo conectados à rede podem ser ensinados por professores que desenvolvem suas práticas pedagógicas de maneira sequenciada, lenta e pouco atrativa. $\mathrm{O}$ autor fala, que esse é um dos maiores problemas da educação na atualidade. As pessoas responsáveis diretamente pela educação desses nativos digitais, no caso pais e professores tiveram acesso às tecnologias de modo tardio. Esses imigrantes digitais, não conseguem compreender que enquanto as crianças assistem televisão, ouvem músicas no celular, jogam elas estão aprendendo e que esse ato além de divertido e prazeroso, é de certa forma educativo.

Uma das maiores dúvidas com as quais os Imigrantes Digitais (pais e professores) se deparam é: devemos obrigar nossas crianças Nativas Digitais a aprender nossos métodos antigos ou devemos nós, imigrantes digitais, aprender o novo? A resposta, acredito, é óbvia. (PRENSKY, 2010, p. 61).

Diariamente, pais e professores identificados por Prensky (2010), como imigrantes digitais, se perguntam como ensinar os nativos digitais de maneira que o aprendizado tenha significado, considerando que os perfis das crianças mudaram. Aceitar essa nova realidade ajudaria, desejarem um novo modelo de educação, pois os procedimentos utilizados na educação hoje, na grande maioria das vezes são os mesmo de 30, 40 anos atrás. Isso é um entrave, pois o sistema educacional arcaico e analógico do país não foi desenvolvido para a era digital e seus falantes nativos da linguagem dos computadores, celulares e internet.

Essas habilidades cognitivas e a capacidade de focar em várias coisas ao mesmo tempo, respondendo automaticamente a estímulos inesperados, não são características novas desenvolvidas pelos indivíduos, mas a intensidade como tudo isso acontece é que fazem os nativos digitais tão diferentes das gerações passadas, ou seja, os alunos estão aí nas salas de aulas e para eles a metodologia tradicional é muito pouco, ou quase nada do que eles procuram.

É notório que a convivência social educa, transforma e às vezes determina, mas é na escola que se tem acesso à educação formal, assim o professor tem um papel importante na nossa sociedade, no processo de transformação da informação em conhecimento e essa construção deve ser compartilhada, intensa, articulada, afetuosa, motivada e bem planejada para que ocorra o aprendizado. 


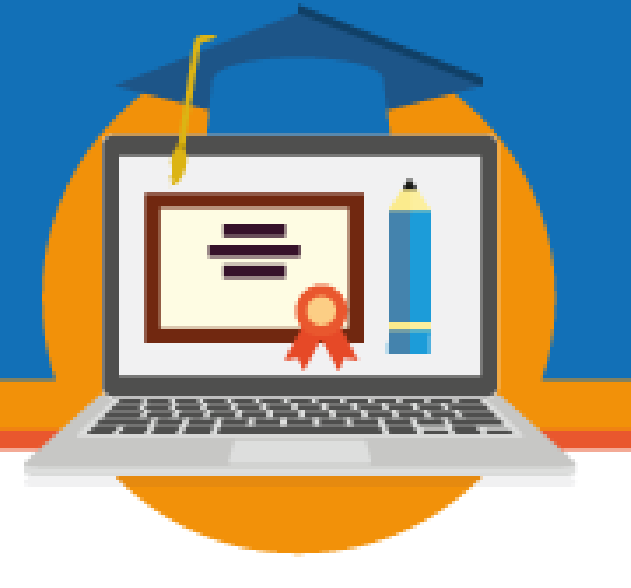

Identificar o estilo de aprendizagem de um aluno significa identificar as formas que ele aprende melhor e, por consequência, como pode obter maior sucesso nos estudos. A partir daí, é possível replanejar o currículo e o programa, a sala de aula e os ambientes virtuais de aprendizagem para ativar e manter a concentração dos alunos, gerando maior retenção do conhecimento. (MATTAR, 2010, p. 3).

Generalizar a forma de aprendizagem pode ser um dos erros mais cometidos ao planejar uma aula, uma vez que individualmente a capacidade de assimilação, acomodação e retenção de conhecimento é única. O ideal seria que os professores fizessem um levantamento, para depois adequar suas práticas de ensino ao estilo de aprendizado de seus alunos. "Em resumo a geração net aprende fazendo (não lendo manuais ou assistindo palestras), trabalhando em grupo e interagindo", (MATTAR, 2010, p. 14).

Essa geração contempla crianças nascidas entre 1980 e 1994, mas que somente nos anos 2000, tornaram-se foco de estudos para professores e pesquisadores da área educacional, que perceberam que uma nova cultura de aprendizagem, estava surgindo a partir da utilização das tecnologias, das mídias. Essa mudança de comportamento diante das competências e habilidades com que lidam com os recursos tecnológicos mudaram os caminhos da comunicação e levaram os educadores a buscar novas metodologias para desenvolverem os conteúdos aplicados em sala de aula.

\section{METODOLOGIAS ATIVAS DE APRENDIZAGEM: REPENSANDO O PROCESSO DE ENSINO/APRENDIZADO}

Figura I - Metodologias ativas 


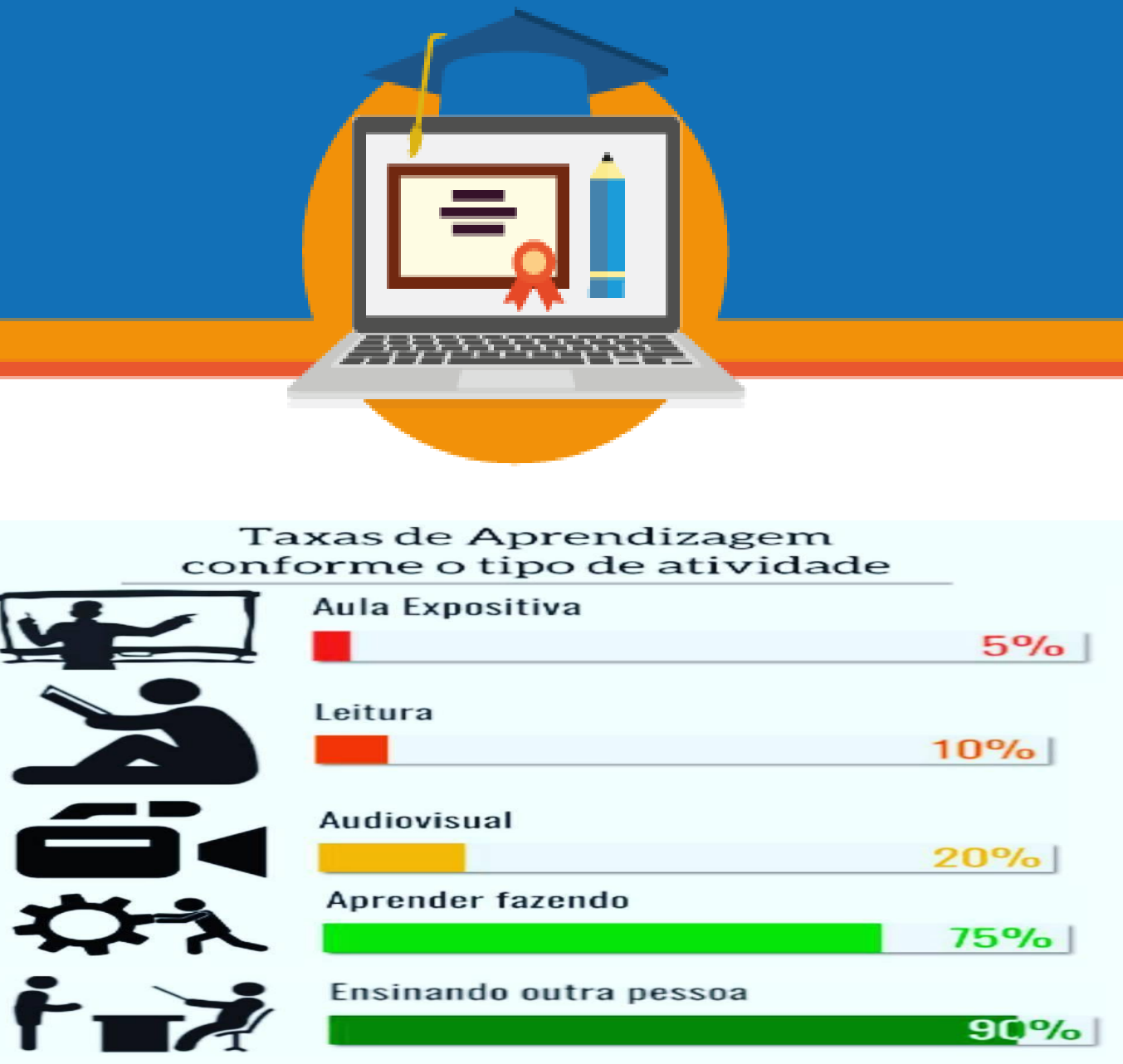

Fonte: Holderbaum (2017).

A figura que abre a apresentação desta sessão, é representativa das Metodologias Ativas de Aprendizagem, que para nós acrescentando tecnologias educacionais, pode ser uma possibilidade de utilização da forma correta no universo escolar, pois proporciona o envolvimento do aluno no processo de ensino/aprendizado com criticidade, atribuindo-lhes corresponsabilidade, buscando envolvê-los na construção do conhecimento com significado, relacionando-o com a vida cotidiana, para isso,

[...] são necessários programas contínuos de formação pedagógica, assim como programas para aperfeiçoar a fluência dos professores em tecnologia da informação, para que eles possam atender melhor às necessidades da geração net. E, é claro que eles sejam remunerados decentemente. (MATTAR, 2010, p. 53).

Como estamos conectados em rede, quase que 24 horas por dia é impossível desassociar educação de tecnologia. É necessário que modificações ocorram com urgência, conduzindo seus alunos as novas experiências de aprendizagem dentro e fora da sala de aula. Moran (2011), diz que o professor é um agente direto no processo de transformação e as metodologias ativas tais como jogos, atividades baseadas em problemas, situações reais ou simuladas são um possível caminho para o desenvolvimento do pensamento crítico e reflexivo na tomada de decisões em práticas sociais.

Figura II - Princípios que constituem as metodologias ativas de ensino 


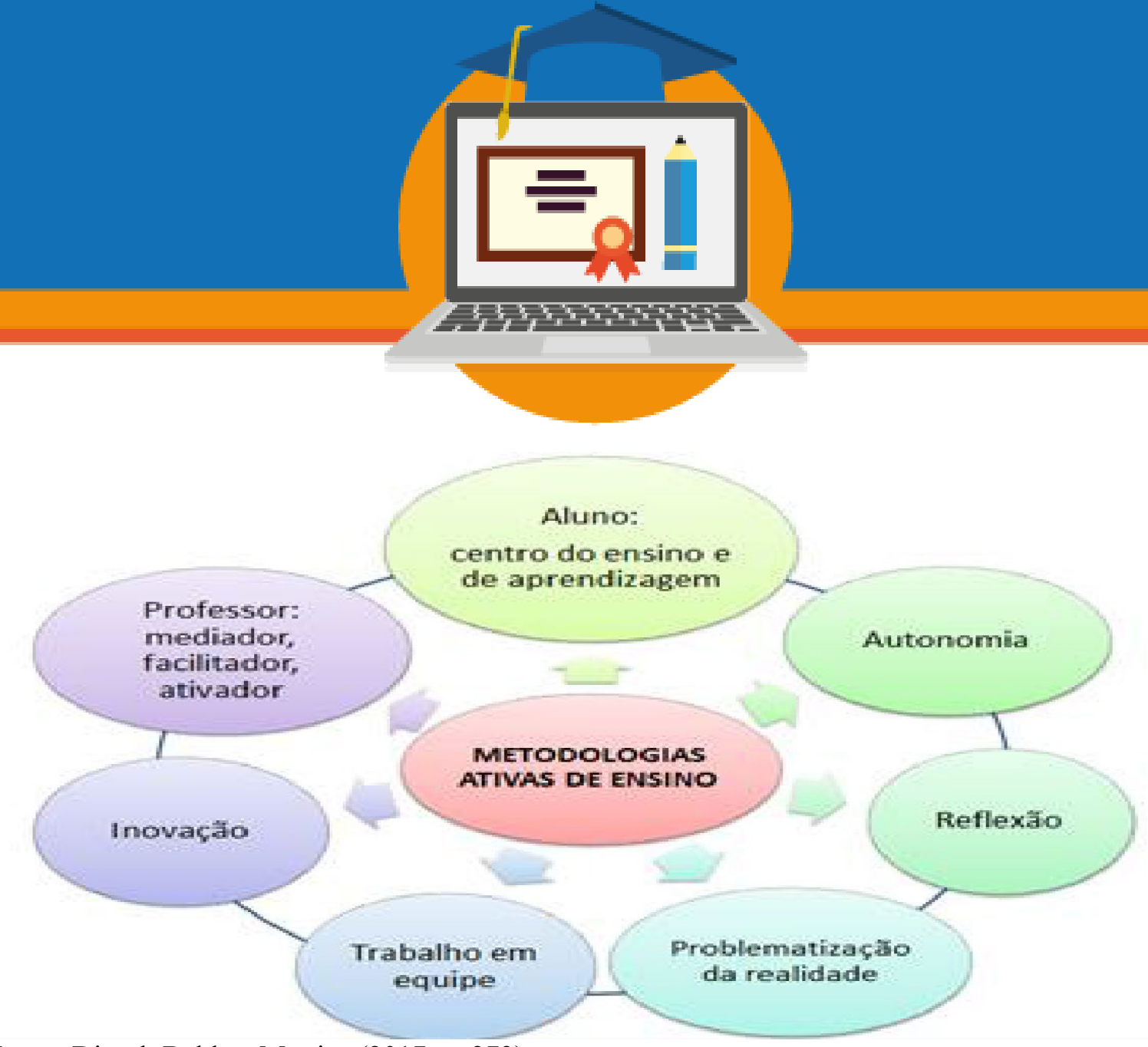

Fonte: Diesel; Baldez; Martins (2017, p. 273).

Isso foi destacado, em recente evento científico organizado pela Pontifícia Universidade Católica de São Paulo (PUC/SP), onde pesquisadores de todo país se reunirão com o comitê organizador para amplo debate no Fórum Metodologias Ativas 2015. Em mensagem aos participantes publicada nos Anais do Fórum Metodologias Ativas (MetA - 2015) John Paul Hempel Lima escreve que:

Pensar em metodologias ativas é pensar no estudante. É pensar no futuro da educação e no futuro do Brasil. Uma educação ativa promove uma sociedade proativa, com estudantes que participam, colaboram e produzem. Promove um pensamento crítico e reflexivo sobre os problemas e desafios de nossa sociedade. Transforma o olhar do estudante frente a seu aprimoramento e do meio em que está inserido. Evoluir nos processos de ensino é sinal de respeito à sociedade e uma resposta dos educadores às mudanças sociais. (LIMA, 2015, p. 1).

Concordamos com o autor que precisamos evoluir nesses aspectos e as metodologias ativas podem ser um caminho. Os direcionamentos acima servem como ponto de referência para a participação ativa em todo o processo escolar, permitindo que esse aluno tome posse do conhecimento e seja um propagador.

Entretanto pensar que o implemento de tecnologias nas escolas dará conta de transformar nossa realidade, que sozinha é sinal de mudança, é utopia. Essas transformações 


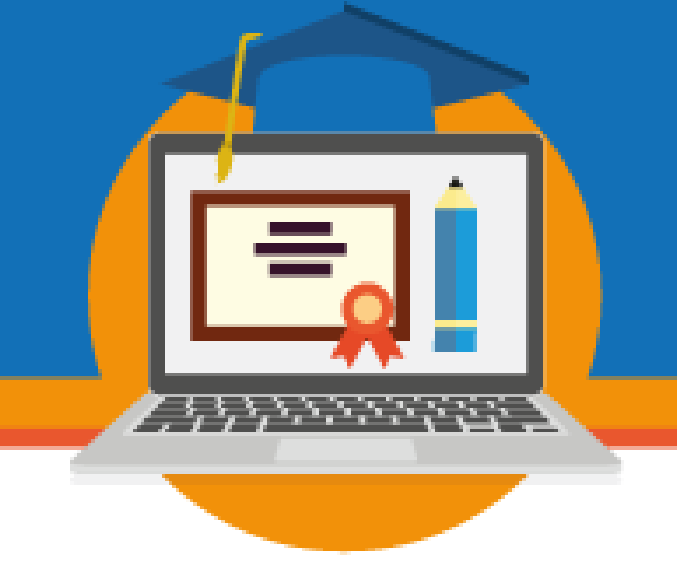

que a comunidade escolar almeja (valorização da escola pública, dos professores, educação de qualidade, aprendizagem permanente), segundo pesquisas científicas podem ocorrer quando todos estiverem engajados com a educação.

Segundo Tardif (2002), os professores constituem em razão de seu número e da função que desempenham, um dos mais importantes grupos ocupacionais e uma das principais peças das sociedades modernas, Uma vez que os avanços tecnológicos, o colapso do capital na sociedade contemporânea, o número de trabalhadores que cada vez mais perdem empregos devido ao fechamento de postos de serviços, tem colocado sobre os ombros dos professores mais uma responsabilidade, preparar um futuro profissional que seja hábil e competente para o mercado de trabalho.

Torna-se importante evidenciar que quando essas adequações não ocorrem, há uma tendência do sistema estatal de culpabilizar somente o professor, o que deve ser entendido, é que não se podem mudar as práticas pedagógicas no contexto de sala de aula, sem recursos materiais, sem formação e sem apoio (TARDIF, 2002). É notório que alguns governantes disseminam para a população, que a educação é a solução de todos os problemas da humanidade, até mesmo a fome, a miséria, e ainda que a utilização das tecnologias como recurso pedagógico nas escolas é a salvação das instituições públicas, quando na verdade estão precárias pela falta de verbas e manutenção de toda natureza.

Nesse sentido, Moran (2013), escreve que que as instituições necessitam de mestres menos "falantes", mais "práticos". De menos aulas informativas e mais atividades de pesquisa e experimentação, de desafios e projetos. Nesse contexto, não é mais necessário resolver tudo no contexto de sala de aula, o aprendizado encontra-se em movimento constante, em diversos espaços.

\section{MÉTODOS}

Com relação aos princípios metodológicos, o presente artigo apresenta o recorte de uma pesquisa de TCC, de natureza qualitativa, do tipo estudo de caso como modalidade de pesquisa. Para desenvolvermos o nosso estudo de caso, a organização metodológica teve etapas como a) 


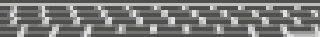

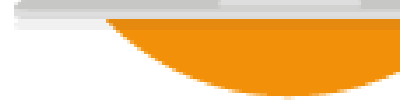

pesquisa bibliográfica/documental; b) pesquisa de campo; c) análise do material coletado. Antes de convidarmos os sujeitos para participarem da pesquisa (observação nas STE, questionários/entrevistas), fomos as Secretarias de Educação da rede redes e ao NTE fazer a solicitação formal aos responsáveis, apresentando-lhes o Termo de Consentimento Livre e Esclarecido, onde foram convidadas duas escolas públicas. Uma escola da rede estadual situada no centro da cidade e outra da rede municipal localizada na periferia, ambas possuem Sala de Tecnologia Educacional (STE) ${ }^{2}$.

$\mathrm{Na}$ escola estadual o número de computadores é proporcional à quantidade de aluno, bem como vários recursos midiáticos, condições materiais que possibilitariam aos professores que suas atividades fossem desenvolvidas, caso optassem por utilizar esses equipamentos em suas práticas pedagógicas. Na ocasião em que fomos a campo (início do $2^{\circ}$ semestre de 2017), na escola estadual um fato nos chamou atenção, a STE tinha cadastro de reserva feito pelos professores até o final daquele ano. Já a escola municipal é uma das poucas que possuem Sala de Tecnologia Educacional no município.

Durante a pesquisa de campo realizamos entrevistas/aplicamos questionários com os professores que atuam nos anos iniciais do ensino fundamental, os profissionais responsáveis pelo funcionamento e manutenção das STE e um representante do Núcleo de Tecnologias Educacionais de Aquidauana (MS) que é o órgão responsável pela formação tecnológica dos educadores e PROGETECs ${ }^{3}$. No período em que estivemos em campo, foram entrevistados onze sujeitos do sexo masculino e feminino com idade média entre 20 e 60 anos de idade. Todos os dados foram registrados em um caderno de campo que serão apresentados no tópico a seguir.

\section{RESULTADOS E DISCUSSÕES}

\footnotetext{
${ }^{2}$ A Sala de Tecnologia Educacional (STE) é um espaço educacional dentro da unidade escolar nomeado dessa forma por possibilitar que o professor utilize as diversas tecnologias disponíveis na escola. Logo, não privilegia o uso do computador, mas significa a possibilidade de utilização de toda e qualquer tecnologia que possa ser aplicada para o enriquecimento do processo educativo. (MATO GROSSO DO SUL, 2015, p. 41).

${ }^{3}$ [...] professor responsável pelo gerenciamento da Sala de Tecnologia Educacional (STE) e dos demais recursos tecnológicos e midiáticos da unidade escolar com a função de facilitador quanto à incorporação desses recursos na prática pedagógica. (MATO GROSSO DO SUL, 2015, p. 43).
} 


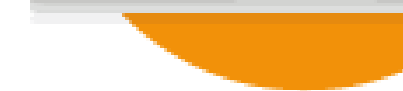

Os dados coletados através do questionário e das entrevistas demonstram que todos os entrevistados são professores regentes e Professor Gerenciador de Tecnologias Educacionais (PROGETEC) ${ }^{4}$. Tínhamos a intenção de responder as seguintes interrogações: com qual frequência esses educadores utilizam as STE? Recebem formação tecnológica inicial e continuada? Os programas e softwares educacionais eram atualizados para atender as necessidades de suas práticas pedagógicas e a realidade cotidiana dos alunos?

Os dados coletados tornaram-se contraditórios, pois os professores regentes da rede estadual relatam que não tem dificuldades para utilização de tecnologias educacionais na prática docente, porém não frequentam as formações oferecidas pelo NTE, utilizam as STEs e os recursos disponíveis na maioria das vezes de forma inadequada (entrevista concedida por um PROGETEC da rede estadual - fonte: caderno de campo, 05/10/2017).

Já na rede municipal, os professores apontaram falta de conhecimentos mínimos, como manuseio e funções das máquinas pela falta de formação, número de máquinas que não atendem as necessidades da escola e a falta de tempo de planejar a aula ao recurso escolhido devido à quantidade de afazeres pedagógicos. Percebemos que a maior parte dos professores que atuam nos anos iniciais do ensino fundamental tem idade entre 40 (quarenta) e 50 (cinquenta) anos de idade, onde $80 \%$ dos profissionais são mulheres.

Com relação ao tempo que exercem a profissão 45,5\% dos professores atuam a mais de 20 anos na educação, demonstrando que a maioria tem larga experiência no exercício da docência. Dos profissionais que responderam ao questionário $78 \%$ eram professores regentes (concursados e convocados) e 18\% eram PROGETECs. Para o desenvolvimento de suas aulas $72,7 \%$ dos educadores responderam que utilizam todos os recursos inclusive os tecnológicos, entretanto esses dados revelam uma contradição, em entrevista realizada com os PROGETEC's das duas redes, os mesmos afirmaram que os professores continuam apegados a práticas docentes tradicionais, baseadas no livro didático e nas cópias de atividades, pouco frequentam

\footnotetext{
${ }^{4}$ [...] professor responsável pelo gerenciamento da Sala de Tecnologia Educacional (STE) e dos demais recursos tecnológicos e midiáticos da unidade escolar com a função de facilitador quanto à incorporação desses recursos na prática pedagógica. (MATO GROSSO DO SUL, 2015, p. 43).
} 
a STE e eventualmente utilizam os recursos disponibilizados como multimídia lousa digital dentre outros.

Outro dado que nos chamou atenção foi que $18,2 \%$ dos professores responderam que costumam utilizar a sala de tecnologias educacionais mais de 10 vezes por mês em atividades variadas, porém na entrevista de um dos PROGETEC em uma das escola da rede estadual, os educadores utilizavam a sala de tecnologias com uma frequência exagerada, mas que a demanda diminuiu depois que houve uma reunião com os professores orientando-lhes que as práticas desenvolvidas na STE teriam que ser planejadas em parceria entre eles (PROGETEC, Professores, Coordenador(a) pedagógico(a)), o que não acontecia anteriormente.

Os professores queriam segundo o PROGETEC, que ele planejasse a aula e a desenvolvesse, assim os professores poderiam utilizar o tempo livre para fazerem outras atividades como planos de aulas, correção de provas, atualização de diários dentre outros afazeres pedagógicos, o que se distancia do que preconizam os grandes pesquisadores da área, pois o professor deve participar ativamente de todo o processo (MORAN, 2013).

Já na rede municipal, a STE é pouco frequentada pelos professores, quando utilizada é para que os alunos desenvolvam pequenos textos, ou naveguem na internet livremente sem um planejamento, principalmente quando falta algum professor.

Outro ponto de investigação foi se esses profissionais possuíam alguma dificuldade em utilizar as tecnologias educacionais em sala de aula, 83,3\% responderam que sim, outra contradição nas respostas dos entrevistados, no que diz respeito às dificuldades que os professores têm para utilizar as tecnologias educacionais em sala de aula, pois a maior parte respondeu que não possuem. Aqui cabe outra reflexão, quando comparamos com as respostas dos PROGETECs. Se não apresentam nenhuma dificuldade, por que não as utilizam? Nesse movimento dialético de pesquisar, percebemos que enquanto buscamos respostas para os questionamentos inicialmente levantados no projeto de pesquisa, medidas que vamos fazendo as análises surgem novas indagações para futuras pesquisas.

Com relação à pergunta dissertativa: de que forma (quais conteúdos/atividades?). Você utiliza as tecnologias educacionais como recurso pedagógico nos anos iniciais do ensino 


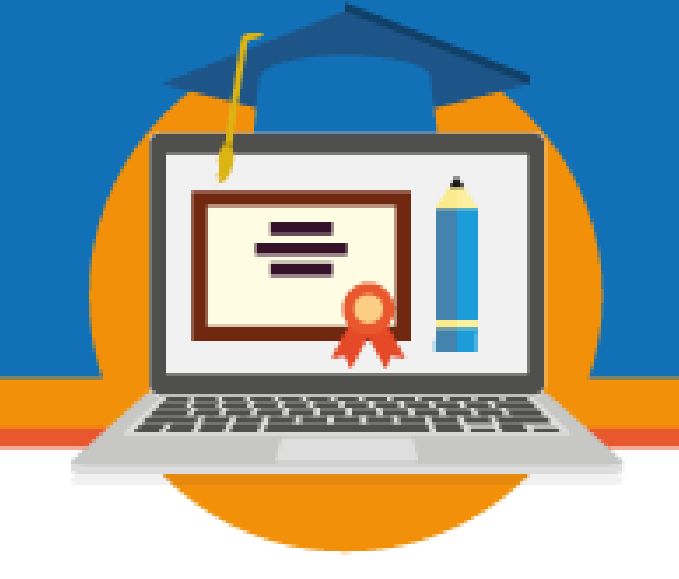

fundamental? As respostas foram: jogos educativos, vídeos, criação de hipertextos, pesquisa na web, construção de imagens, gráficos, estudo de mapas e sites educacionais.

Já a pergunta feita sobre a existência programas de formação continuada na escola que atuam, todos os professores da rede estadual responderam que já participaram de formações. Já os professores da rede municipal em sua grande maioria responderam que não tiveram essa formação e os que tiveram afirmam que não foi suficiente, pois continuam com as mesmas dificuldades.

Um dos (as) professores (as) da rede estadual citou que as capacitações oferecidas ficam centradas nos conhecimentos teóricos, que acha relevante, mas gostaria que as formações tivessem um caráter mais prático, com metodologias ativas que priorizassem a ação em si e não a teoria.

De acordo com a entrevista realizada com um profissional do NTE do município, a falta de formação dos docentes pode ser justificada pela falta de tempo dos professores, pelo excesso de jornada de trabalhos (alguns chegam a trabalhar até três turnos diariamente), restando lhes apenas os finais de semana e período de recesso escolar para descansarem e é justamente quando as formações acontecem. Em relação à periodicidade em que os programas e softwares educacionais utilizados pela escola são atualizados, na rede municipal o profissional respondeu que a última atualização ocorreu há três anos. Já o PROGETEC da rede estadual, respondeu que os softwares e programas educacionais são atualizados, mas não informou com qual frequência e qual a última atualização.

\section{CONSIDERAÇÕES FINAIS}

Concluímos afirmando, que as tecnologias educacionais são relevantes para auxiliar os professores em suas práticas docentes, pois permitem aprendizados e interações entre os alunos. Esclarecemos que a presente pesquisa, não tem a intenção de apresentar culpados, mas evidenciar que se as tecnologias forem utilizadas como recurso educacional de maneira articulada no ambiente escolar servirá para o desenvolvimento de novas competências, de forma dinâmica pode contribuir para transformar a informação em conhecimento quando utilizadas 
de forma correta. Desse modo, para que sejam utilizadas de forma correta é necessário que se tenham um planejamento, um o objetivo bem definido, para que os professores utilizem a melhor forma o recurso a ser utilizado em determinadas disciplinas/conteúdos. Para que isso aconteça, é necessário o apoio da coordenação pedagógica e dos PROGETECs.

Finalizamos afirmando que é necessário que as metodologias ativas estejam presentes no cotidiano escolar, principalmente nos anos iniciais do ensino fundamental, pois os nativos digitais que estão matriculados nesta etapa precisam ser estimulados a produzirem conhecimento desde a mais tenra idade, oportunizando lhes aprendizados com significado, através de problematizações contextualizadas com a complexa vida cotidiana, fazendo com que sejam sujeitos críticos, reflexivos capazes de contribuir com a sociedade que está inserida.

As vivencias no período de estágio, a participação em vários projetos de extensão durante o Curso de Pedagogia, nos permitiram observar as dificuldades que os professores tinham para a utilização e adaptação das tecnologias educacionais ao conteúdo proposto. $\mathrm{O}$ fato nos instigou a pesquisar a prática docente e a utilização das Tecnologias Educacionais nos anos iniciais do ensino fundamental, em duas escolas de redes diferentes. No momento, com a pesquisa já concluída, os resultados revelaram que os fatos estão relacionados à falta de formação continuada dos professores.

Portanto, diante do exposto, percebemos que para que haja mudanças no ensino se faz necessário que os educadores também mudem suas concepções e práticas docentes. Por esta razão, ressaltamos que a temática necessita ser mais discutida no município, pois mesmo diante de tantos afazeres pedagógicos, os professores precisam receber formação continuada condizente, visando sempre à melhoria do processo de ensino e aprendizagem da educação básica.

Por fim, acreditamos que uma alternativa para solução do problema, é o NTE disponibilizar um cronograma de formação para as duas redes de ensino, no período de trabalho dos professores e não no final de semana, quando eles utilizam o pequeno tempo para descansar da dura jornada de trabalho em função da baixa remuneração, visto que precisamos de práticas docentes que coloquem o alunado no centro do processo de ensino, cultivando assim o espírito 


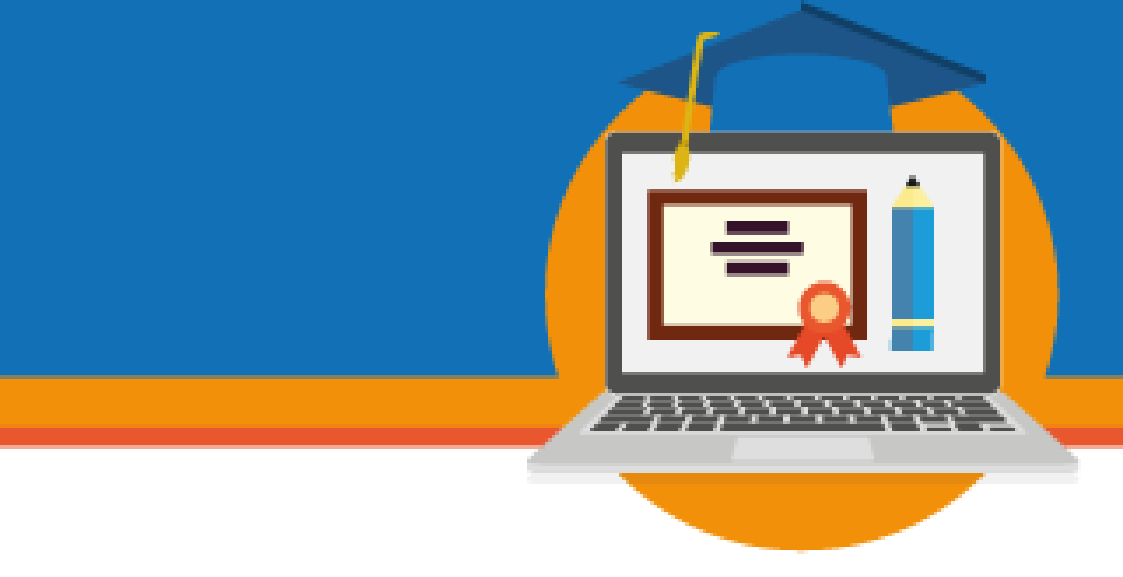

de colaboração, de reflexão e de criticidade, para que tenham uma postura protagonista numa sociedade que anseiam por cidadãos proativos.

\section{REFERÊNCIAS}

ABREU, Rosane Albuquerque dos Santos. Desafios e conflitos no cotidiano da sala de aula. In: FREITAS, Maria Tereza de Assunção et. al. Cibercultura e formação de professores. Belo Horizonte: Autêntica editora, 2009.

ALMEIDA, Maria Elizabeth Bianconcini de. Informática e formação de professores. ProInfo. v. 2. Secretaria de Educação a Distância. Brasília: Ministério da Educação, SEED, 2000.

BRASIL. Lei n ${ }^{\circ}$ 9.394, de 20 de dezembro de 1996. Estabelece as diretrizes e bases da educação nacional. Diário Oficial da República Federativa do Brasil, Brasília, DF, 20 de dezembro de 1996. Disponível em: <http://www.planalto.gov.br/ccivil_03/leis/L9394.htm>. Acesso: $01 / 11 / 2017$.

CASTELLS, Manuel. O poder da comunicação. Rio de Janeiro: Paz e Terra, 2015.

DIESEL, Aline. BALDEZ, Alda Leila Santos. MARTINS, Silvana Neumann. Os princípios das metodologias ativas de ensino: uma abordagem teórica. Revista Thema, Pelotas - RS, v. 14, n. 1, pp. 268-288, 2017.

FREITAS, Maria Tereza de Assunção. Et e tal. Cibercultura e formação de professores. Belo Horizonte: Autêntica Editora, 2009.

JENKINS, Henry. Cultura da convergência. Google Books, 2015. Acesso: 04/02/2017.

KENSKI, Vani Moreira. Novas tecnologias: o redimensionamento do espaço e do tempo e os impactos no trabalho docente. Revista Brasileira de Educação. n. 08, p. 58-71, mai./ago. 1998.

LIMA, John Paul Hempel. Saberes da Universidade: Metodologias Ativas. Anais do Fórum Metodologias Ativas META, 2015. Disponível em: <http://www.pucsp.br/reunindo-saberesda-universidade>. Acesso: 15 jul. 2017.

MATTAR, João. Games em educação: como os nativos digitais aprendem. São Paulo: Pearson Prentice Hall, 2010.

MATO GROSSO DO SUL. Secretaria de Estado de Educação/MS (SED). Manual do Gestor Escolar. Campo Grande - MS, 2015. 


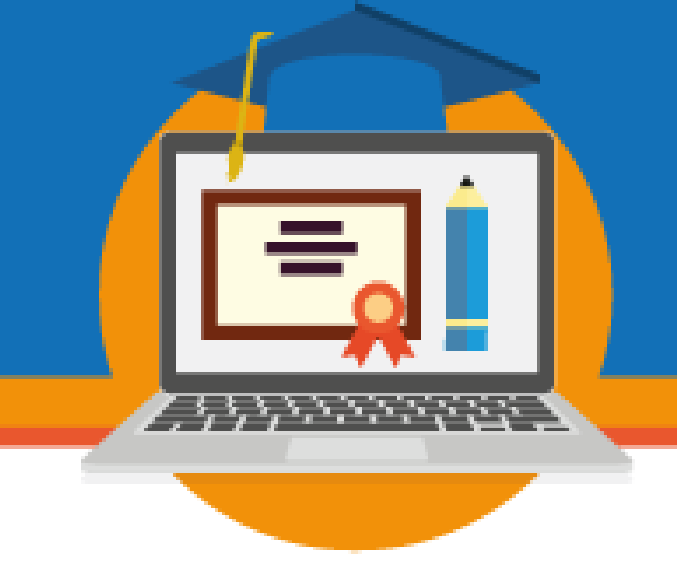

MORAN, José Emanuel. Novas tecnologias e o re-encantamento do mundo. Revista Tecnologia Educacional, Rio de Janeiro, v. 23, n. 126, p. 24-26, Setembro-Outubro. 1995.

MORAES, Roque; GALIAZZI, Maria do Carmo. Análise textual discursiva. Ijuí/RS: Editora Inijuí, 2007.

NOGUEIRA, Makeliny O. G. LEAL, Daniela. Teorias de aprendizagem: um encontro entre os pensamentos filosófico, pedagógico e psicológico. Curitiba: InterSaberes, 2015.

PIERRE, Lévy. Cibercultura. São Paulo: Ed. 34, 1999. In: Google Books. Acesso: 27/02/2017.

PRENSKY, Mark. "Não me atrapalhe, mãe - estou aprendendo!": como os videogames estão preparando os nossos filhos para o sucesso no século XXI - e como você pode ajudar! São Paulo: PHORTE, 2010.

TARDIF, Maurice. Saberes docentes e formação profissional. Petrópolis/RJ: Vozes. 2002.

TIC educação 2016. Apresentação dos principais resultados. Disponível em: $<\mathrm{http}: / /$ www.cetic.br/media/analises/tic_educacao_2016_coletiva_de_imprensa.pdf $>$. Acesso: 24/08/2017. 